\title{
Article
}

\section{Higher Anxiety Is Associated with Lower Cardiovascular Autonomic Function in Female Twins}

\author{
Zeynep Nas ${ }^{1}$, Harriëtte Riese ${ }^{2}$, Arie M. van Roon ${ }^{3}$ and Frühling V. Rijsdijk ${ }^{1}$ \\ ${ }^{1}$ Social, Genetic and Developmental Psychiatry Centre, Institute of Psychiatry, Psychology and Neuroscience, King's College London, London, UK, ${ }^{2}$ University of \\ Groningen, University Medical Center Groningen, Department of Psychiatry, Interdisciplinary Center Psychopathology and Emotion Regulation, Groningen, the \\ Netherlands and ${ }^{3}$ Department of Internal Medicine, Division of Vascular Medicine, University of Groningen, University Medical Center Groningen, Groningen, the \\ Netherlands
}

\begin{abstract}
Anxiety symptoms co-occur with cardiovascular health problems, with increasing evidence suggesting the role of autonomic dysfunction. Yet, there is limited behavior genetic research on underlying mechanisms. In this twin study, we investigated the phenotypic, genetic and environmental associations between a latent anxiety factor and three cardiovascular autonomic function factors: interbeat interval (IBI, time between heart beats), heart rate variability (HRV, overall fluctuation of heart-beat intervals) and baroreflex sensitivity (BRS, efficiency in regulating blood pressure [BP]). Multivariate twin models were fit using data of female twins $(N=250)$ of the Twin Interdisciplinary Neuroticism Study (TWINS). A significant negative association was identified between latent anxiety and BRS factors $(r=-.24$, 95\% CI [-.40, -.07]). Findings suggest that this relationship was mostly explained by correlated shared environmental influences, and there was no evidence for pleiotropic genetic or unique environmental effects. We also identified negative relationships between anxiety symptoms and HRV $(r=-.17,95 \%$ CI $[-.34, .00])$ and IBI factors $(r=-.13,95 \%$ CI $[-.29, .04])$, though these associations did not reach statistical significance. Findings implicate that higher anxiety scores are associated with decreased efficiency in short-term BP regulation, providing support for autonomic dysfunction with anxiety symptomatology. The baroreflex system may be a key mechanism underlying the anxiety-cardiovascular health relationship.
\end{abstract}

Keywords: Anxiety; cardiovascular; autonomic dysfunction; baroreflex sensitivity; interbeat interval; heart rate variability

(Received 21 January 2020; accepted 30 March 2020)

Anxiety symptoms are common, and if excessive in magnitude, duration and frequency, can lead to clinical anxiety (MallorquíBagué et al., 2016; Mehta et al., 2003). Both symptomatic and clinical anxiety co-occur with cardiovascular health problems (Allgulander, 2016; Celano et al., 2016; Chang et al., 2016; Emdin et al., 2016; Janszky et al., 2010; Pratt et al., 2016; Vogelzangs et al., 2010). Longitudinally, anxious individuals have an elevated risk of coronary heart disease (CHD), independent of demographic variables (e.g., age), biological risk factors (e.g., family history) and lifestyle/health behaviors (e.g., exercise; Roest et al., 2010). Somatic symptoms of anxiety, such as heart palpitations, are also associated with an increased CHD risk in women (Nabi et al., 2010), highlighting a physiological, autonomic pathway in which anxiety may link to cardiovascular events (Celano et al., 2016).

Autonomic dysfunction, an imbalance between parasympathetic and sympathetic control, may contribute to this cardiovascular burden. To test this, cardiovascular autonomic functioning has been measured using three indices: baroreflex sensitivity (BRS), interbeat interval (IBI) and heart rate variability (HRV). BRS reflects efficiency in responding to blood pressure (BP) changes. Short-term

Author for correspondence: Zeynep Nas, Email: zeynep.nas@kcl.ac.uk Cite this article: Nas Z, Riese H, van Roon AM, and Rijsdijk FV. (2020) Higher Anxiety Is Associated with Lower Cardiovascular Autonomic Function in Female Twins. Twin Research and Human Genetics 23: 156-164, https://doi.org/10.1017/thg.2020.47 regulation of $\mathrm{BP}$ is achieved through baroreceptors, which detect an increase in BP, resulting in a reduction of heart rate through inhibition of sympathetic activity and activation of parasympathetic flow. The inverse occurs when BP is decreasing (Shaffer et al., 2014; Swenne, 2013). There is limited research on the anxiety-BRS relationship and existing studies mainly take a clinical perspective (Mussgay \& Rüddel, 2004).

Nonetheless, anxiety symptoms have been associated with lowered BRS by up to $36 \%$, independent of demographic variables and existing cardiovascular health predictors (Virtanen et al., 2003; Watkins et al., 2002; Watkins et al., 1998). The association is apparent over and above depression (Watkins et al., 1999) and recorded in response to stress, argued to induce a shift in autonomic reactivity (Ginty et al., 2017). Following a stress-inducing task, young adults scoring high on trait anxiety display lower BRS compared to their low trait anxiety peers (SanchezGonzalez et al., 2015). Furthermore, this highly anxious group had an attenuated BRS comparable to a middle-aged sample, suggesting cardiovascular outcomes similar to that produced with aging. Anxiety symptoms may therefore associate with reduced parasympathetic activity both at baseline and in response to stress.

Varying IBIs, the period in between successive heartbeats, is a marker of healthy cardiovascular autonomic functioning (Costa et al., 2017). Typically measured as the time between ' $R$ ' peaks on an electrocardiogram (ECG), IBI is also referred to as the 
'RR interval.' Clinical anxiety studies suggest shorter IBIs, indicative of increased heart rate with low variability (Hoehn-Saric et al., 1991; Thayer et al., 1996).

HRV can be defined as the overall fluctuation of heart period over time (Chalmers et al., 2014). HRV can be indexed using several methods, including based on IBI time series (e.g., mean interbeat interval, $\mathrm{mIBI}$ ), or frequencies (low, $\mathrm{LF}_{\mathrm{IBI}}, 0.04-0.15 \mathrm{~Hz}$; and high, $\mathrm{HF}_{\mathrm{IBI}}, 0.15-0.40 \mathrm{~Hz}$ ) and nonlinear techniques (e.g., Poincaré plots). Being a common marker of psychological wellbeing, cardiovascular health and mortality (Chalmers et al., 2014; Kemp \& Quintana, 2013), HRV has been negatively associated with anxiety phenotypes. For example, HRV as measured in short time periods in the high-frequency band has been associated with generalized anxiety (Chang et al., 2013b; Yeragani et al., 2006), panic disorder (Chang et al., 2013a; Wang et al., 2013) and social anxiety (Gaebler et al., 2013; Pittig et al., 2013). As with BRS and IBI studies, research focus is on clinical anxiety, which does not represent its dimensional, quantitative nature in the population (Bjelland et al., 2009; Kircanski et al., 2017).

There is also sparse research on what underlies this autonomic dysfunction. According to neurobiological models (Friedman, 2007; Thayer \& Lane, 2000), anxiety reflects poor inhibition of cognitive (e.g., worry), affective (e.g., panic), behavioral (e.g., avoidance) and physiological (e.g., increased heart rate) responses, reducing autonomic and physiological flexibility (Thayer et al., 2010). Sex differences have also been reported, whereby women show decreased parasympathetic activity in comparison to men (Fiol-Veny et al., 2018; Koenig et al., 2017), though findings are inconclusive, with other studies indicating increased heart variability in women (Snieder et al., 2007). There is also limited behavioral genetic research on the common genetic (pleiotropy) and environmental influences that could link the two domains as they appear in the normal population. Twin studies are imperative in understanding this relative contribution to individual differences in traits, as done with anxiety symptoms previously (Ask et al., 2014; López-Solà et al., 2014; Nivard et al., 2015; Petkus et al., 2016). Previous studies, using the same sample as used here, suggest genetic influences on BRS, high frequency band $\left(\mathrm{HF}_{\mathrm{IBI}}\right)$ and $\mathrm{mIBI}$, plus on the relationship between neuroticism and BRS (Riese et al., 2006, 2007). Yet, these parameters have not been investigated in the context of anxiety symptoms.

This behavioral genetics study uses a genetically sensitive twin design to explore: (1) how anxiety symptoms correlate with the three cardiovascular autonomic measures (mIBI, $\mathrm{HF}_{\mathrm{IBI}}, \mathrm{BRS}$ ), (2) the extent to which individual differences in anxiety symptoms and cardiovascular autonomic measures are determined by latent genetic and environmental factors and (3) the genetic and environmental underpinning of the associations between the two domains.

\section{Materials and Methods}

\section{Participants}

This study capitalizes on the Twin Interdisciplinary Neuroticism Study (TWINS; Riese et al., 2013), of the Groningen Twin Register (GTR) in the north of the Netherlands. Monozygotic (MZ) and dizygotic (DZ) twins were identified for the GTR based on being born between 1972 and 1992 from the same mother with identical birth dates. In the current study, we used data from a subset of female twin pairs $(N=250)$ aged $18-30$ who participated in a laboratory session as part of TWINS. Individuals with existing cardiovascular health problems were not considered for inclusion of the study. The study was given ethical approval by the Ethics Committee at the University Medical Center Groningen, and all individuals provided written consent (METc 2000/060e).

\section{Measures}

Anxiety symptoms. We included four measures of anxiety symptoms for each twin. This included a mix of both state and trait measures to gauge an overall anxiety symptoms' composite. First, a trait anxiety sum score was derived from four items in the eight-item Hopkins' Symptom Checklist (HSCL), a validated psychometric tool to measure general psychological distress (Derogatis et al., 1974). Second, a single-item state anxiety score was measured by the Profile of Mood States (POMS) questionnaire (McNair, 1971). Third was a single-item state anxiety measure from the Dutch version of the state-trait anxiety inventory (STAI-DY; Defares et al., 1980). Finally, we included the HSCL anxiety sum score from the co-twin sister, also derived from four items in the HSCL (Twin 1 reporting on Twin 2 and vice versa). This is done to control for self-report bias and decrease variance in self-reported mental health (Kendler et al., 2002; Riese et al., 2007). All measures were treated as continuous, except for the POMS variable, which was entered as a dichotomous variable (as it is originally ordinal data).

Cardiovascular autonomic functioning. Participants were instructed to abstain from intensive physical activity (including sports) and alcohol consumption $24 \mathrm{~h}$ before testing and to fast (including coffee and tea consumption) from 10:00 pm on the evening before visiting the lab. Measurement of cardiovascular autonomic functioning has been described in detail elsewhere (Riese et al., 2007, 2013) and outlined in Supplementary Material 1. Briefly, BRS, HRV and mean IBI were measured in an experimental task with four standardized conditions: Rest (R1), stress with visual feedback (S1), stress with auditory feedback (S2) and rest (R2). Participants completed the tasks in a seated posture. In the stress conditions, participants completed a modified version of the 'emotion face dot probe task' (Mogg \& Bradley, 1999), whereby participants indicate whether they saw three or four dots previously occupied by a pair of faces. Visual feedback was presented as the correct answer at the center of the screen for $1000 \mathrm{~ms}$. In the auditory feedback condition, participants' wrong answers were met with $100 \mathrm{~dB}$ of white noise for $500 \mathrm{~ms}$.

Cardiovascular measurements were collected in a sitting position after participants relaxed for $10 \mathrm{~min}$, with each condition lasting approximately $5 \mathrm{~min}$. An ECG was recorded using Ag/AgCl electrodes $\left(3 \mathrm{M}^{\mathrm{Tm}}\right.$ Red $\operatorname{Dot}^{\mathrm{Tm}}$, St Paul, MN, USA) and a custom-made ECG-amplifier and trigger device (ETC-3, DataLab, Faculty of Behavioural and Social Sciences, University of Groningen, The Netherlands). A Portapres device continuously measured beat-to-beat BP from the finger (FMS, Finapres Medical Systems $\mathrm{BV}$; Amsterdam, the Netherlands). As respiration is known to influence BRS, changes in respiration signals were recorded with a flexible band placed on the upper thorax connected to an amplifier. ECG, finger BP and respiration were digitized using a data acquisition board (Keithley DAS-12, Keithley Instruments, Inc., USA) at $100 \mathrm{~Hz}$. Custom-made PreCar 3.0 (Greaves-Lord et al., 2010) software was used for R-peak detection (at \pm 2 ms accuracy) and artefact correction (i.e., IBI time series with supraventricular extra systoles were excluded). 
Table 1. General characteristics of the twin sample with means (SD)

\begin{tabular}{lcc} 
& $\begin{array}{c}\text { Monozygotic } \\
(N=148)\end{array}$ & $\begin{array}{c}\text { Dizygotic } \\
(N=102)\end{array}$ \\
\hline Age in years & $22.56(3.76)$ & $22.45(3.35)$ \\
\hline Anxiety measures & & \\
\hline $\begin{array}{l}\text { Profile of Mood states (ANX 1) } \\
\text { O= No/minimal anxiety; } \\
1=\text { Report level of anxiety }\end{array}$ & $0=137 / 148(93 \%)$ & $0=93 / 102(91 \%)$ \\
$1=9 / 102(9 \%)$ & & $32.25(6.37)$ \\
\hline $\begin{array}{l}\text { State anxiety (ANX 2) } \\
\text { Range: } 20-53\end{array}$ & $30.58(5.74)$ & $3.06(2.88)$ \\
\hline $\begin{array}{l}\text { HSCL Anxiety sum score (ANX 3) } \\
\text { Range: } 0-15\end{array}$ & $2.68(2.25)$ & $2.10(2.77)$ \\
\hline $\begin{array}{l}\text { HSCL Anxiety sibling score (ANX 4) } \\
\text { Range: } 0-15\end{array}$ & $2.15(2.16)$ & \\
\hline
\end{tabular}

Note: The Profile of Mood states variable is ordinal in nature and we have therefore reported proportions.

mIBI (mean of the interbeat intervals, ms), $\mathrm{HF}_{\mathrm{IBI}}$ (power of interbeat intervals in the high frequency band $0.15-0.40 \mathrm{~Hz}$, $\mathrm{ms}^{2}$ ) and BRS (gain or modulus, between systolic BP and IBI, in the frequency band $0.07-0.14 \mathrm{~Hz}, \mathrm{~ms} / \mathrm{mmHg}$ ) were calculated using the CARSPAN spectral analysis program (Mulder, 1988; Riese et al., 2007; Robbe et al., 1987), a method that has been previously used (Althaus et al., 2004; Dietrich et al., 2006; Lefrandt et al., 1999; Van Roon et al., 2004). More details on exclusion criteria can be found in Supplementary Material 1.

\section{Statistical Analyses}

Prior to statistical analyses, the effects of age, body mass index $\left(\mathrm{BMI}, \mathrm{kg} / \mathrm{m}^{2}\right.$ ), medication-use, systolic and diastolic BP were regressed out of the cardiovascular autonomic variables in SPSS version 12.0.2 (SPSS Inc., Chicago, IL, USA) to take these confounders into consideration without losing statistical power. Of the MZ twins $(N=148), 15$ individuals reported medication use $(1=$ antihypertensive, $14=$ other, not cardioactive, medication). Of the $\mathrm{DZ}$ twins $(N=102), 32$ individuals used medication ( $2=$ antihypertensives, $30=$ other, not cardioactive, medication $)$. Those using cardioactive medications were excluded from the analysis. The effect of medication is found to be marginal (Riese et al., 2006), we therefore decided to account for its effect by regressing this out prior to analyses.

As for BP, this was regressed out due to its known influence on vascular stiffness (including carotid artery stiffness) and can thus influence BRS (Mukai et al., 2003). We also regressed out the effects of age from the anxiety variables in $\mathrm{R}$ statistical environment and subsequently used residuals in the analysis.

\section{Twin Model Fitting Analysis}

We analyzed the relationships between anxiety and the three cardiovascular autonomic function measures in a multivariate twin model. The classical twin design rests on the comparison between $\mathrm{MZ}$ and DZ twins; MZ twins share 100\%, whereas DZ twins share on average $50 \%$ of their segregating DNA. We initially estimated similarity in $\mathrm{MZ}$ and $\mathrm{DZ}$ twin pairs within and across traits (twin correlations). Using biometrical structural equation modeling (SEM), variance of traits is further decomposed into three latent factors: additive genetic influences $(A)$; common/shared environmental influences $(C)$, which contribute to twin pair similarity (e.g., environmental factors affecting both twins in one family) and nonshared environmental factors $(E)$, which contribute to differences between twins within one pair (including random measurement error).

Through standardization, the A, C and $\mathrm{E}$ factors represent proportion of variance. For example, heritability $\left(a^{2}\right)$ of a trait is the proportion of variance in that trait due to genetic differences in the population. The same principle applies for standardizing environmental influences $\left(c^{2}\right.$ and $\left.e^{2}\right)$. Covariance between traits is also decomposed into etiological correlations (denoted $r_{\mathrm{A}}, r_{\mathrm{C}}$ and $r_{\mathrm{E}}$ ), which suggest the extent to which the $\mathrm{A}, \mathrm{C}$ and $\mathrm{E}$ factors underlying variance for one trait also affect the other. Using this etiological information, the phenotypic correlation $(\mathrm{rPh})$ between anxiety and cardiovascular autonomic measures can also be decomposed.

Our multivariate model features a latent anxiety factor $\left(\mathrm{L}_{\mathrm{ANX}}\right)$, ascertained by the twins' self-reported anxiety and co-twin sisters' report (four measures). The latent $\mathrm{BRS}, \mathrm{HF}_{\mathrm{IBI}}$ and $\mathrm{mIBI}$ factors ( $\mathrm{L}_{\mathrm{BRS}}, \mathrm{L}_{\mathrm{HF}}, \mathrm{L}_{\mathrm{IBI}}$ ) were each determined by four measurements during the experimental conditions. In addition to specific measurement error, we also modeled a 'rater-bias' component for the anxiety variables. This considers the additional covariance between a twin's self-report and what is reported by the co-twin and separates rater bias and unreliability from the latent anxiety factor. The analyses in this article follow previous procedures using the same sample (Riese et al., 2007) with model-fitting conducted in the OpenMx package in R (Neale et al., 2016; Neale \& Miller, 1997). The full model-fitting procedure is further detailed in Supplementary Material 2.

\section{Results}

Table 1 presents general characteristics of the sample and Table 2 details means $(S D)$ for the four experimental conditions.

\section{Phenotypic Factor Model}

The phenotypic factor model (Figure 1) obtains correlations between the latent anxiety and the three cardiovascular autonomic factors $(-2 \log \mathrm{L}=11457.38, d f=3542, \mathrm{AIC}=4373.381)$. Latent anxiety significantly negatively correlated with BRS $(r=-0.24$, 95\% CI $[-.42,-.05])$. The relationship between latent anxiety and $\mathrm{mIBI}$ was also negative but nonsignificant $(r=-.15,95 \%$ CI $[-.33, .03])$ and the same with $\mathrm{HF}_{\mathrm{IBI}}(r=-.16,95 \% \mathrm{CI}$ $[-.34, .03])$. Table 3 outlines these phenotypic $(\mathrm{rPh})$ and other intraclass correlations.

\section{Genetic Factor Model}

The full genetic SEM model, estimating all parameters $(-2 \mathrm{LL}=11408.13, d f=3510, \mathrm{AIC}=4388.129)$, was used as a comparison for nested submodels to determine the model with best fit. The final model fixed the $\mathrm{A}$ and $\mathrm{C}$ specific effects (on measured variables) to zero, apart from one A specific effect on the state anxiety variable (as it was too substantial to drop from the model). There was no significant reduction in fit between the full and final model, and a lower AIC observed $(\Delta-2 \mathrm{LL}$ $[\Delta d f]=23.35[31], p=.84)$. We henceforth report results of the final model (Figure 2).

Standardized variance components $\left(a^{2}, c^{2}\right.$ and $\left.e^{2}\right)$ of each latent factor were estimated (Table 4$)$, with heritability $\left(a^{2}\right)$ estimates being moderate and significant for mIBI. Genetic correlations were not significant between latent anxiety and any of the cardiovascular 
Table 2. Means $(S D)$ for $B R S, m I B I$ and $\mathrm{HF}_{|B|}$ in each of the four experimental conditions

\begin{tabular}{lcccc} 
& \multicolumn{4}{c}{ Experimental condition } \\
\cline { 2 - 4 } Cardiovascular autonomic function measure & Rest 1 & Stress 1 & Stress 2 & Rest 2 \\
\hline BRS $(\mathrm{ms} / \mathrm{mmHg})$ & $9.25(3.65)$ & $8.56(3.31)$ & $8.84(3.58)$ & $8.65(3.66)$ \\
\hline $\mathrm{IBI}$ mean $(\mathrm{ms})$ & $770.33(107.77)$ & $755.51(113.14)$ & $747.78(109.71)$ & $758.32(110.73)$ \\
\hline $\mathrm{HRV}-\mathrm{HF}_{\mathrm{IBI}}\left(\log \left[\mathrm{ms}^{2}\right]\right)$ & $6.89(.90)$ & $6.67(.83)$ & $6.69(.84)$ & $6.78(.89)$ \\
\hline
\end{tabular}

Note: BRS, Baroreflex sensitivity; mIBI, mean IBI; $\mathrm{HF}_{\mathrm{IB}}$, Heart rate variability with IBI power in the $0.15-0.40 \mathrm{~Hz}$ frequency band.

Table 3. Twin correlations within and across traits $(95 \% \mathrm{Cl})$ for $\mathrm{MZ}$ and $\mathrm{DZ}$ twins separately

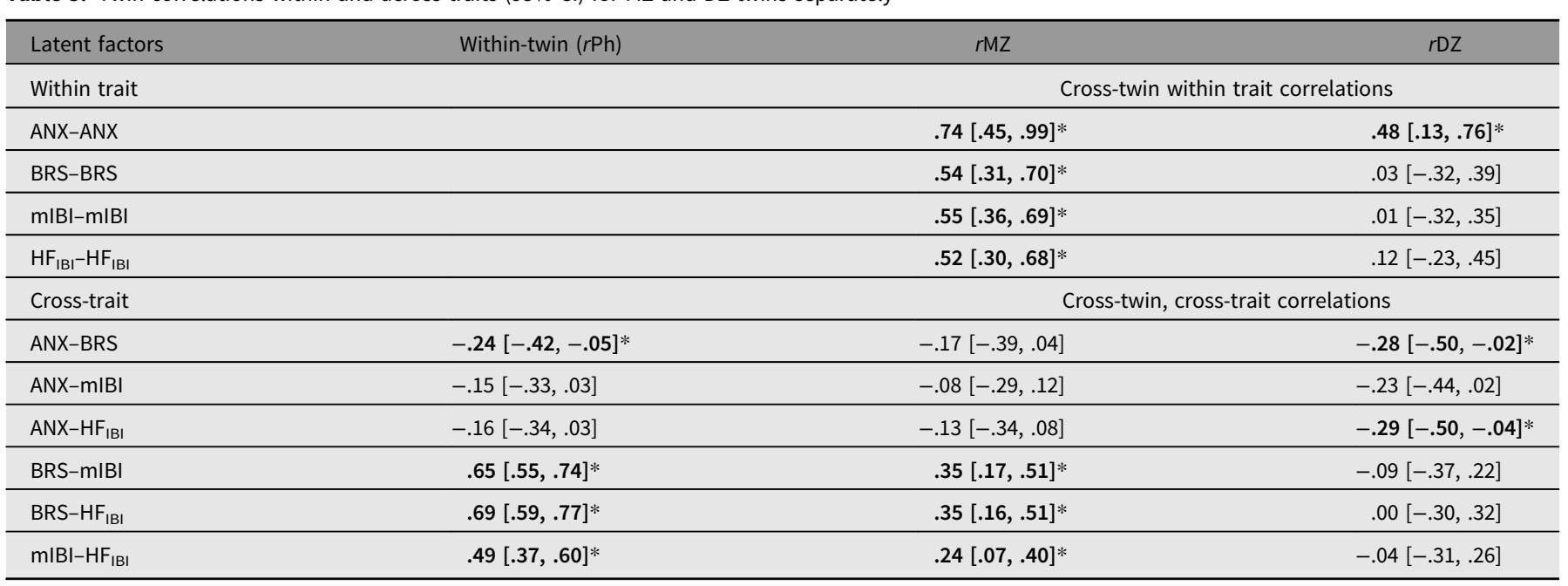

Note: Correlations derived from the Phenotypic Common Pathway model. $r$ Ph, phenotypic correlation, that is, the within-twin cross-trait correlations; $r \mathrm{MZ}$, monozygotic twin correlation; $r D Z$, dizygotic twin correlation; ANX, Anxiety; BRS, Baroreflex sensitivity; mIBI, latent interbeat-interval factor; $\mathrm{HF}_{\mathrm{IBI}}$, heart rate variability with IBI power in the $0.15-0.40 \mathrm{~Hz}$ frequency band. $\mathrm{HF}_{\mid \mathrm{BI}}$ values were log transformed. "Significant correlations in bold type (indicated by the $95 \% \mathrm{Cl}$ not spanning zero).

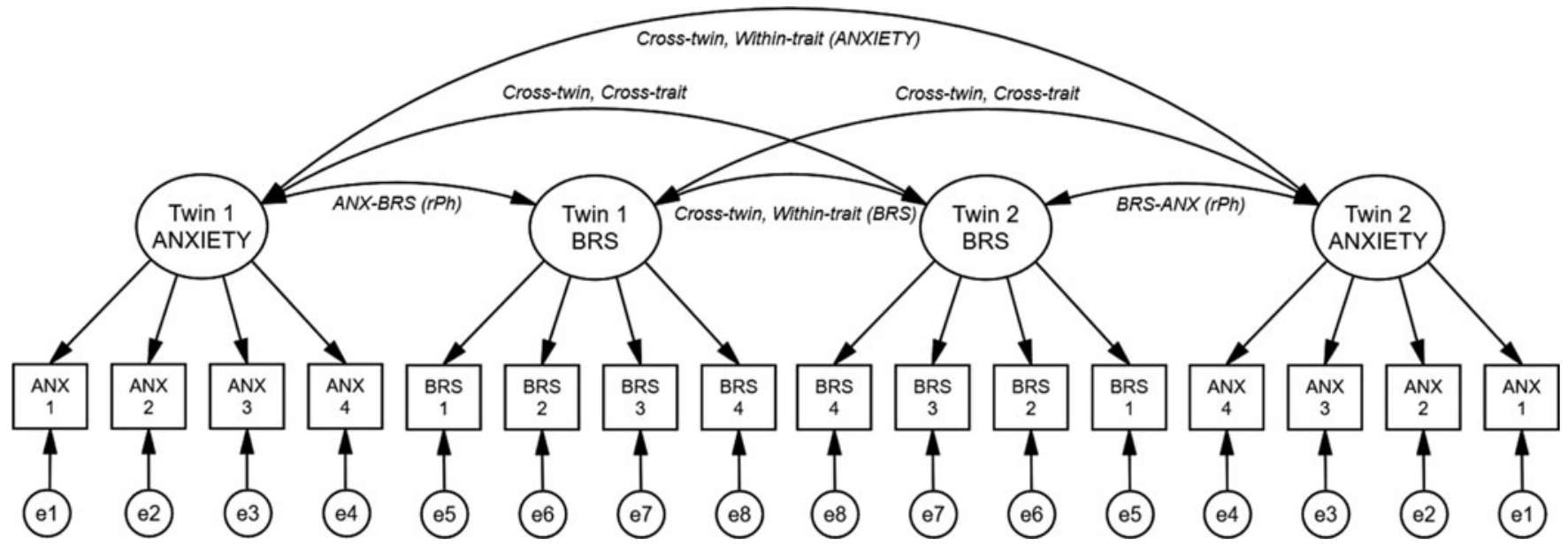

Fig. 1. Phenotypic factor model (including a rater bias component). Note: Phenotypic associations between latent anxiety and baroreflex sensitivity (BRS) factors (for a twin pair). For simplicity, $\mathrm{HRV}\left(\mathrm{HF}_{\mathrm{IBI}}\right)$ and interbeat interval $(\mathrm{mIBI})$ were omitted from this figure. Latent (unobserved) factors are depicted in circles, observed (measured) variables shown in rectangles. Twin 1/2 ANXIETY, latent anxiety factor for twin 1/2; Twin 1/2 BRS, latent baroreflex sensitivity factor for twin 1/2. Anx 1, Profile of Mood states anxiety; Anx 2, State anxiety; Anx 3, Hopkin's Symptom checklist anxiety; Anx 4, Co-twin sibling report of anxiety via the Hopkins symptom checklist. BRS 1-4, four measurements of BRS during the experimental task. Arrows running from latent factors to measured variables indicate path loadings, paths between latent factors represent the phenotypic correlations. ANX-BRS $(\mathrm{rPh})$, phenotypic correlation between latent factors. Cross-twin, within-trait (ANXIETY/BRS), correlations across twins, within latent anxiety and BRS factors; cross-twin, cross-trait, correlations across twins and across latent anxiety and BRS factors; e1-e8, specific unique environmental effects on the measured variables. 
Table 4. Standardized variance components $(95 \% \mathrm{Cl})$ of latent factors

\begin{tabular}{lccc}
\hline Latent factor & \multicolumn{1}{c}{$\mathrm{a}^{2}$} & $\mathrm{c}^{2}$ & $\mathrm{e}^{2}$ \\
\hline ANXIETY & $.42[.00, .88]$ & $.31[.00, .72]$ & $.27[.09, .54]^{*}$ \\
\hline $\mathrm{BRS}$ & $.42[.00, .66]$ & $.09[.00, .47]$ & $.49[.32, .72]^{*}$ \\
\hline $\mathrm{mlBI}$ & $.44[.07, .65]^{*}$ & $.08[.00, .39]$ & $.48[.33, .67]^{*}$ \\
\hline $\mathrm{HF}_{\mathrm{IBI}}$ & $.35[.00, .64]$ & $.15[.00, .50]$ & $.50[.34, .71]^{*}$ \\
\hline
\end{tabular}

Note: Contribution of genetic $\left(a^{2}\right)$, common environmental $\left(c^{2}\right)$ and unique environmental $\left(e^{2}\right)$ influences on the variance of the latent anxiety and the three autonomic factors. BRS, Baroreflex sensitivity; $\mathrm{mIBI}$, latent interbeat-interval factor; $\mathrm{HF}_{\mathrm{IB}}$, heart rate variability.

*Bold type indicates significance (indicated by the $95 \% \mathrm{Cl}$ not spanning zero).

Table 5. Genetic and environmental correlations ( $95 \% \mathrm{Cl}$ ) between latent factors

\begin{tabular}{lccc}
\hline $\begin{array}{l}\text { Latent } \\
\text { factors }\end{array}$ & $\begin{array}{c}\text { Genetic } \\
\text { correlation }\left(r_{\mathrm{g}}\right)\end{array}$ & $\begin{array}{c}\text { Common } \\
\text { environmental } \\
\text { correlation }\left(r_{\mathrm{c}}\right)\end{array}$ & $\begin{array}{c}\text { Unique } \\
\text { environmental } \\
\text { correlation }\left(r_{\mathrm{e}}\right)\end{array}$ \\
\hline ANX-BRS & $-.18[-1,1]$ & $-.86[-1,1]$ & $-.06[-.43, .34]$ \\
\hline ANX-mIBI & $-.13[-1,1]$ & $-.90[-1,1]$ & $-.14[-.47, .21]$ \\
\hline ANX-HF $_{\mathrm{IBI}}$ & $-.13[-1,1]$ & $-.99[-1,1]$ & $.00[-.36, .37]$ \\
\hline BRS-mIBI & $.66[-1,1]$ & $.55[-1,1]$ & $.67[.49, .81]^{*}$ \\
\hline $\mathrm{BRS}-\mathrm{HF}_{\mathrm{IBI}}$ & $.63[-1,1]$ & $.82[-1,1]$ & $.73[.54, .86]^{*}$ \\
\hline $\mathrm{mIBI}-\mathrm{HF}_{\mathrm{IBI}}$ & $.33[-1,1]$ & $.93[-1,1]$ & $.55[.34, .71]^{*}$ \\
\hline
\end{tabular}

Note: *Significant correlations shown in bold (indicated by the $95 \% \mathrm{Cl}$ not spanning zero). autonomic measures (Table 5), with BRS $\left(r_{\mathrm{g}}=-.18,95 \% \mathrm{CI}\right.$ $[-1,1])$; with mIBI $\left(r_{\mathrm{g}}=-.13\right.$, 95\% CI $\left.[-1,1]\right)$ or with $\mathrm{HF}_{\mathrm{IBI}}$ $\left(r_{\mathrm{g}}=-.13,95 \%\right.$ CI $\left.[-1,1]\right)$. We did, however, find that the phenotypic relationship between anxiety-BRS was mostly explained by shared environmental influences (58\%). Rater bias components were nonsignificant for all the anxiety variables.

\section{Discussion}

This study investigated the genetic and environmental etiology and relationships between a latent anxiety and three cardiovascular autonomic function factors; $\mathrm{BRS}, \mathrm{mIBI}$ and $\mathrm{HRV}$ in the $\mathrm{HF}_{\mathrm{IBI}}$. We report a significant negative correlation between the latent anxiety and BRS factors, mostly driven by shared environmental influences. We did not obtain significant genetic or environmental correlations.

\section{Etiology of Anxiety and Autonomic Measures}

We report moderate heritability estimates for the latent anxiety and cardiovascular autonomic measures (35-44\%) with the estimate for mIBI being significant. Heritability of the anxiety factor is consistent with previous literature (López-Solà et al., 2014; Nivard et al., 2015). Although the estimates for the autonomic measures are lower than those of a previous study using the same sample, reporting heritability estimates $\sim 50 \%$ (Riese et al., 2007), the confidence intervals are wide in both studies, indicating the need for larger sample sizes to increase certainty around the point

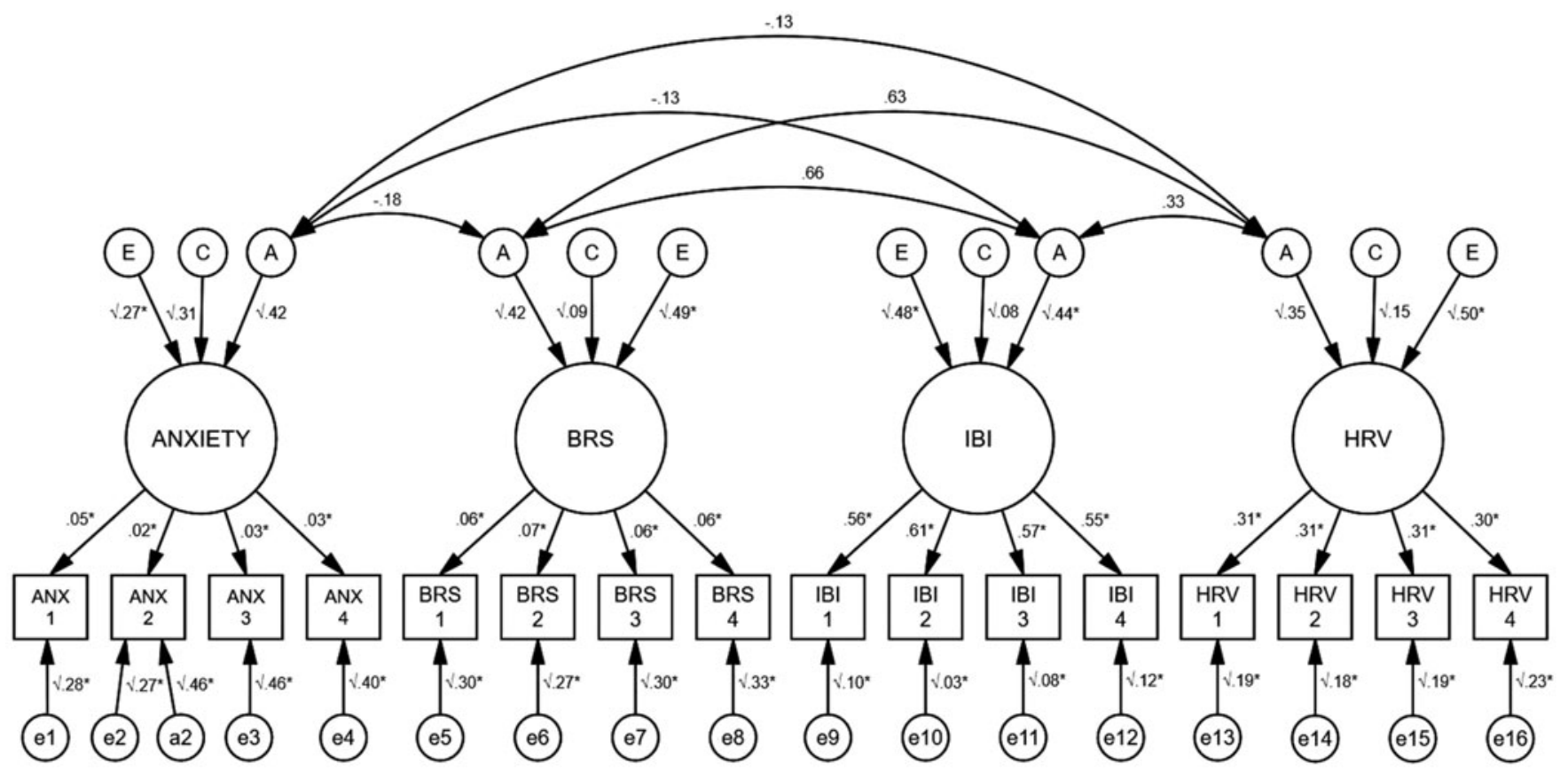

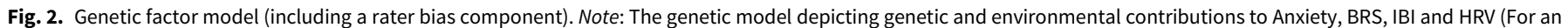

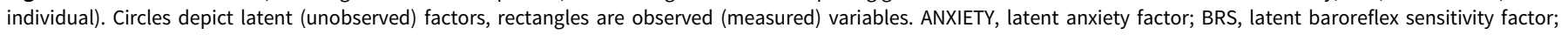

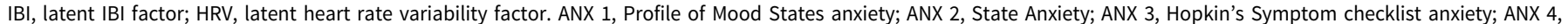

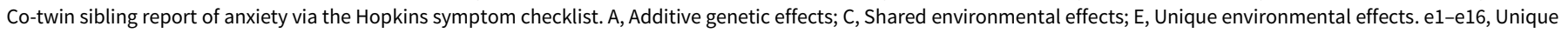

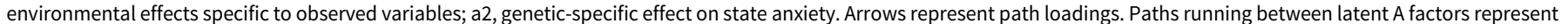

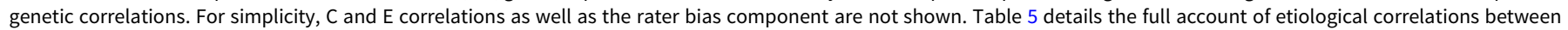
factors. 
estimates. There are also other possible reasons for this: first, our study fits a latent anxiety factor rather than neuroticism, a different psychological construct, which can change the correlation structure of the twin model. Our cross-twin, cross-trait correlations (Table 3) suggest a higher influence of shared environmental effects explaining covariance between factors, whereas this pattern is reversed in the previous paper (where MZ correlations were higher than DZ, suggesting more genetic influence), although again with wide confidence intervals.

Second, we report a different final model compared to the previous paper and have kept the substantial specific genetic influence on state anxiety as opposed to dropping the parameter completely. Third, our analyses used OpenMx (Neale et al., 2016), a relatively new modeling package with a different optimizer than that used in the previous study. Taken together, replication of this study in a larger sample is required to improve precision in estimating genetic and environmental effects.

\section{Relationships between Anxiety and Cardiovascular Autonomic Measures}

Higher scores on a latent anxiety factor were correlated with lower $\mathrm{BRS}$, suggesting reduced ability to respond to, and regulate $\mathrm{BP}$ with increasing levels of anxiety. Negative correlations were also found between anxiety-IBI and $\mathrm{HF}_{\mathrm{IBI}}$ but did not reach significance. This may highlight a specific link not only between anxiety-BRS but also necessitates further evidence, as this is currently the first twin study combining the three cardiovascular autonomic measures with anxiety. Nevertheless, our results lend support to the neurovisceral integration model, whereby autonomic flexibility may be reduced with elevated levels of anxiety and stress (Friedman, 2007). We did not, however, find evidence for pleiotropic genetic effects. Aside from sample size, our participants are relatively healthy in terms of anxiety symptoms, creating a restricted range of scores, possibly decreasing power further. The relationship could also be largely environmentally driven, as supported by previous work on cardiovascular autonomic functioning with genetic effects being minimal (Osztovits et al., 2011). The phenotypic relationship between anxiety and BRS was mostly accounted for by shared environmental influences. These are environments that make twins similar, such as the home environment, school attended and peer groups. These environments may foster an anxious profile for the twins reducing BRS or vice versa. Nevertheless, this should be interpreted with caution, given that the shared environmental correlation is nonsignificant and difficulty in pinpointing exact environmental factors from this study alone.

\section{Strengths}

Our study has several strengths. This is, to our knowledge, the first multivariate twin analysis combining anxiety symptoms (both state and trait anxiety) with all three cardiovascular autonomic measures (mIBI, $\mathrm{HF}_{\mathrm{IBI}}$, BRS). Anxiety was investigated in a dimensional, symptom-based context as opposed to a diagnostic perspective, tapping into the anxiety spectrum rather than a relatively restricted range of scores. Second, our study offers a behavior genetic perspective. Although previous work suggests negative associations between anxiety symptoms and measures of autonomic function, they do not employ twin analyses into the phenotypic, genetic and environmental relationships. Although we were likely underpowered to detect such genetic and environmental effects, our design allowed us to also test these parameters. Our finding of a negative association between anxiety and BRS directly supports previous research and adds to the role of autonomic dysfunction with anxiety phenotypes (Sanchez-Gonzalez et al., 2015; Virtanen et al., 2003; Watkins et al., 2002). Third, we controlled for various confounders, including BMI and medication, and as our study was made up of a homogeneous female sample, results were not confounded by sex and a wide age span.

\section{Limitations and Future Directions}

First, we were limited by our small female sample. Although eliminating sex- and age-specific confounds, replication is required in larger samples for increased statistical power. It is also worth including males, considering sex differences in anxiety and autonomic functions reported at the phenotypic and genetic level (Koenig et al., 2017; McLean \& Anderson, 2009). Also, both anxiety (Lee et al., 2016) and cardiovascular health (North \& Sinclair, 2012; Paneni et al., 2017) are influenced by age, prompting further research with different age groups. Furthermore, genetic and environmental influences can be age dependent, such that new age-specific factors may emerge over time (Franić et al., 2010). A longitudinal twin design can best decipher the stability and change in such genetic and environmental influences.

Second, we measured autonomic functioning in a laboratory setting, with 5-min recordings for each condition. While this may not reflect everyday autonomic functioning, experimental tasks are a widely used, accurate method to investigate autonomic performance (Chalmers et al., 2016; Riese et al., 2006, 2007). Shortterm measurements of autonomic functions have been found to be highly reliable, especially with healthy adults (Sandercock et al., 2005). Future studies, however, may use the growing work on ambulatory assessment of anxiety and cardiovascular functioning in real time through mobile, wearable technology. This can provide data that are both longitudinal and reflective of everyday tasks. Third, as autonomic functions were measured at one time-point in the TWINS study, we were limited by a cross-sectional design. Although causal inference (e.g., between anxiety and BRS) is not possible here, future work may focus on designs that are closer to establishing causality, including longitudinal research and combining causal inference methods with the twin design (Minică et al., 2018).

Fourth, our findings are based on European participants. Results may differ across non-Western samples, especially considering culture-specific anxiety syndromes (Koydemir \& Essau, 2018) and differences in cardiovascular health according to ethnicity (El-Gabalawy et al., 2014; Li et al., 2009). Further cross-cultural research that incorporates genetically sensitive designs may decipher similarities and differences in anxiety and cardiovascular health markers.

Finally, our results are preliminary. Although we find that environmental influences shared between twins mostly explain the overlap between anxiety and lower baroreflex control, genetic influences should not be ruled out. More recently, genome-wide association studies (GWAS) have begun highlighting common genetic variants associated with anxiety (Alves et al., 2017; Gottschalk \& Domschke, 2017; Purves et al., 2019) and cardiovascular functions (Nolte et al., 2017; Sigurdsson et al., 2018). This approach provides insight into genetic etiology at a molecular level and paves the way for polygenic risk scores to identify individuals at-risk for anxiety and autonomic dysfunction. There is, therefore, scope to expand on the twin design reported here. Future clinical applications may involve screening individuals with 
anxiety for cardiovascular autonomic dysfunction to identify and prevent future cardiovascular complications.

\section{Conclusion}

In conclusion, higher scores on a latent anxiety factor were associated with lower BRS and shared environmental factors may possibly underlie this. The ability to respond to and regulate BP may therefore be compromised by increasing levels of anxiety symptoms. Higher anxiety was also related to lower interbeat interval (mIBI) and $\mathrm{HRV}\left(\mathrm{HF}_{\mathrm{IBI}}\right)$, but these associations were not significant. We did not find evidence for pleiotropic effects (i.e., relationships due to shared genetic influences), although further research with larger sample sizes is required to determine these findings. Our results suggest a link between anxiety and lower baroreflex control and add to the literature on the governing role of autonomic dysfunction in the associations between anxiety and cardiovascular health.

Supplementary material. To view supplementary material for this article, please visit https://doi.org/10.1017/thg.2020.47.

Acknowledgments. The TWINS was supported by the Netherlands Organisation for Health Research and Development (ZonMw 904-57-130), and the UK-Netherlands Partnership Program in Science (BR 56-481 and BR 96-229) which is jointly run and financed by the British Council and the Netherlands Organization for Scientific Research (NWO). The authors thank the twins for their participation in our research.

Author contributions. ZN and FR conceived the study. FR and HR were involved in the TWINS study formulation and data preprocessing. ZN performed the twin modeling analysis supervised by FR. ZN and FR wrote the manuscript. AR provided expertise regarding the cardiovascular autonomic measures. All authors contributed to manuscript revision, read and approved the submitted version.

\section{Conflict of interest. None.}

Ethical standards. The authors assert that all procedures contributing to this work comply with the ethical standards of the relevant national and institutional committees on human experimentation and with the Helsinki Declaration of 1975 , as revised in 2008 .

\section{References}

Allgulander, C. (2016). Anxiety as a risk factor in cardiovascular disease. Current Opinion in Psychiatry, 29, 13-17.

Althaus, M., Van Roon, A. M., Mulder, L. J. M., Mulder, G., Aarnoudse, C. C., \& Minderaa, R. B. (2004). Autonomic response patterns observed during the performance of an attention-demanding task in two groups of children with autistic-type difficulties in social adjustment. Psychophysiology, 41, 893-904.

Alves, V. de M., Moura, E. L. de, Correia, L. T. A., Nardi, A. E., Alves, V. de M., Moura, E. L. de, ... Nardi, A. E. (2017). Genetic polymorphisms and generalized anxiety disorder: A systematic review. MedicalExpress, 4. https:// doi.org/10.5935/medicalexpress.2017.01.01

Ask, H., Torgersen, S., Seglem, K. B., \& Waaktaar, T. (2014). Genetic and environmental causes of variation in adolescent anxiety symptoms: A multiple-rater twin study. Journal of Anxiety Disorders, 28, 363-371.

Bjelland, I., Lie, S. A., Dahl, A. A., Mykletun, A., Stordal, E., \& Kraemer, H. C. (2009). A dimensional versus a categorical approach to diagnosis: anxiety and depression in the HUNT 2 study. International Journal of Methods in Psychiatric Research, 18, 128-137.

Celano, C. M., Daunis, D. J., Lokko, H. N., Campbell, K. A., \& Huffman, J. C. (2016). Anxiety disorders and cardiovascular disease. Current Psychiatry Reports, 18, 101.

Chalmers, J. A., Heathers, J. A. J., Abbott, M. J., Kemp, A. H., \& Quintana, D. S. (2016). Worry is associated with robust reductions in heart rate variability:
A transdiagnostic study of anxiety psychopathology. BMC Psychology, 4, Article no. 32.

Chalmers, J. A., Quintana, D. S., Abbott, M. J.-A., \& Kemp, A. H. (2014). Anxiety disorders are associated with reduced heart rate variability: A meta-analysis. Frontiers in Psychiatry, 5. https://doi.org/10.3389/fpsyt. 2014.00080

Chang, H.-A., Chang, C.-C., Tzeng, N.-S., Kuo, T. B. J., Lu, R.-B., \& Huang, S. Y. (2013a). Decreased cardiac vagal control in drug-naive patients with panic disorder: A case-control study in Taiwan. Asia-Pacific Psychiatry, 5, 80-89.

Chang, H.-A., Chang, C.-C., Tzeng, N.-S., Kuo, T. B. J., Lu, R.-B., \& Huang, S.-Y. (2013b). Generalized anxiety disorder, comorbid major depression and heart rate variability: A case-control study in Taiwan. Psychiatry Investigation, 10, 326-335.

Chang, W. H., Chen, W. T., Lee, I. H., Chen, P. S., Yang, Y. K., \& Chen, K. C. (2016). Coexisting anxiety disorders alter associations with physical disorders in the elderly: A Taiwan cross-sectional nationwide study. Psychiatry and Clinical Neurosciences, 70, 211-217

Costa, M. D., Davis, R. B., \& Goldberger, A. L. (2017). Heart rate fragmentation: A new approach to the analysis of cardiac interbeat interval dynamics. Frontiers in Physiology, 8. https://doi.org/10.3389/fphys.2017. 00255

Defares, P. B., van der Ploeg, H. M., \& Spielberger, C. D. (1980). Handleiding bij de Zelf-beoordelings Vragenlijst $Z B V$. Een nederlandstalige bewerking van de Spielberger State-Trait Anxiety Inventory. Swets \& Zeitlinger.

Derogatis, L., Lipman, R. S., Rickels, K., Uhlenhuth, E. H., \& Covi, L. (1974). The Hopkins Symptom Checklist (HSCL): A self report symptom inventory. Behavioral Science, 19, 1-15.

Dietrich, A., Riese, H., van Roon, A. M., Engelen, K. van, Ormel, J., Neeleman, J., \& Rosmalen, J. G. (2006). Spontaneous baroreflex sensitivity in (pre)adolescents. Journal of Hypertension, 24, 345-352.

El-Gabalawy, R., Mackenzie, C. S., Pietrzak, R. H., \& Sareen, J. (2014). A longitudinal examination of anxiety disorders and physical health conditions in a nationally representative sample of U.S. Older adults. Experimental Gerontology, 60, 46-56.

Emdin, C. A., Odutayo, A., Wong, C. X., Tran, J., Hsiao, A. J., \& Hunn, B. H. M. (2016). Meta-analysis of anxiety as a risk factor for cardiovascular disease. The American Journal of Cardiology, 118, 511-519.

Fiol-Veny, A., De la Torre-Luque, A., Balle, M., \& Bornas, X. (2018). Diminished heart rate complexity in adolescent girls: A sign of vulnerability to anxiety disorders? Anxiety, Stress, \& Coping, 31, 375-386.

Franić, S., Middeldorp, C. M., Dolan, C. V., Ligthart, L., \& Boomsma, D. I. (2010). Childhood and adolescent anxiety and depression: beyond heritability. Journal of the American Academy of Child \& Adolescent Psychiatry, 49, 820-829.

Friedman, B. H. (2007). An autonomic flexibility-neurovisceral integration model of anxiety and cardiac vagal tone. Biological Psychology, 74, 185-199.

Gaebler, M., Daniels, J. K., Lamke, J.-P., Fydrich, T., \& Walter, H. (2013). Heart rate variability and its neural correlates during emotional face processing in social anxiety disorder. Biological Psychology, 94, 319-330.

Ginty, A. T., Kraynak, T. E., Fisher, J. P., \& Gianaros, P. J. (2017). Cardiovascular and autonomic reactivity to psychological stress: neurophysiological substrates and links to cardiovascular disease. Autonomic Neuroscience : Basic \& Clinical, 207, 2-9.

Gottschalk, M. G., \& Domschke, K. (2017). Genetics of generalized anxiety disorder and related traits. Dialogues in Clinical Neuroscience, 19, 159-168.

Greaves-Lord, K., Tulen, J., Dietrich, A., Sondeijker, F., Roon, A. van, Oldehinkel, A., ... Huizink, A. (2010). Reduced autonomic flexibility as a predictor for future anxiety in girls from the general population: the TRAILS study. Psychiatry Research, 179, 187-193.

Hoehn-Saric, R., McLeod, D. R., \& Zimmerli, W. D. (1991). Psychophysiological response patterns in panic disorder. Acta Psychiatrica Scandinavica, 83, 4-11.

Janszky, I., Ahnve, S., Lundberg, I., \& Hemmingsson, T. (2010). Early-onset depression, anxiety, and risk of subsequent coronary heart disease: 37-year follow-up of 49,321 young Swedish men. Journal of the American College of Cardiology, 56, 31-37. 
Kemp, A. H., \& Quintana, D. S. (2013). The relationship between mental and physical health: insights from the study of heart rate variability. International Journal of Psychophysiology, 89, 288-296.

Kendler, K. S., Prescott, C. A., Jacobson, K., Myers, J., \& Neale, M. C. (2002). The joint analysis of personal interview and family history diagnoses: evidence for validity of diagnosis and increased heritability estimates. Psychological Medicine, 32, 829-842.

Kircanski, K., LeMoult, J., Ordaz, S., \& Gotlib, I. H. (2017). Investigating the nature of co-occurring depression and anxiety: comparing diagnostic and dimensional research approaches. Journal of Affective Disorders, 216, $123-135$.

Koenig, J., Rash, J. A., Campbell, T. S., Thayer, J. F., \& Kaess, M. (2017). A meta-analysis on sex differences in resting-state vagal activity in children and adolescents. Frontiers in Physiology, 8. https://doi.org/10.3389/fphys.2017. 00582

Koydemir, S., \& Essau, C. A. (2018). Anxiety and anxiety disorders in young people: A cross-cultural perspective. In M. Hodes, S. S.-F. Gau, \& P. J. De Vries (Eds.), Understanding uniqueness and diversity in child and adolescent mental health (pp. 115-134). Academic Press.

Lee, L. O., Gatz, M., Pedersen, N. L., \& Prescott, C. A. (2016). Anxiety trajectories in the second half of life: genetic and environmental contributions over age. Psychology and Aging, 31, 101-113.

Lefrandt, J. D., Hoogenberg, K., van Roon, A. M., Dullaart, R. P., Gans, R. O., \& Smit, A. J. (1999). Baroreflex sensitivity is depressed in microalbuminuric Type I diabetic patients at rest and during sympathetic manoeuvres. Diabetologia, 42, 1345-1349.

Li, Z., Snieder, H., Su, S., Ding, X., Thayer, J. F., Treiber, F. A., \& Wang, X. (2009). A longitudinal study in youth of heart rate variability at rest and in response to stress. International Journal of Psychophysiology, 73, 212-217.

López-Solà, C., Fontenelle, L. F., Alonso, P., Cuadras, D., Foley, D. L., Pantelis, C., ... Harrison, B. J. (2014). Prevalence and heritability of obsessive-compulsive spectrum and anxiety disorder symptoms: A survey of the Australian Twin Registry. American Journal of Medical Genetics Part B: Neuropsychiatric Genetics, 165, 314-325.

Mallorquí-Bagué, N., Bulbena, A., Pailhez, G., Garfinkel, S. N., \& Critchley, H. D. (2016). Mind-body interactions in anxiety and somatic symptoms. Harvard Review of Psychiatry, 24, 53-60.

McLean, C. P., \& Anderson, E. R. (2009). Brave men and timid women? A review of the gender differences in fear and anxiety. Clinical Psychology Review, 29, 496-505.

McNair, D. M. (1971). Manual profile of mood states. Educational \& Industrial Testing Service.

Mehta, K. M., Simonsick, E. M., Penninx, B. W. J. H., Schulz, R., Rubin, S. M., Satterfield, S., \& Yaffe, K. (2003). Prevalence and correlates of anxiety symptoms in well-functioning older adults: findings from the Health Aging and Body Composition Study. Journal of the American Geriatrics Society, 51, 499-504.

Minică, C. C., Dolan, C. V., Boomsma, D. I., de Geus, E., \& Neale, M. C. (2018). Extending causality tests with genetic instruments: an integration of Mendelian randomization with the classical twin design. Behavior Genetics, 48, 337-349.

Mogg, K., \& Bradley, B. P. (1999). Orienting of attention to threatening facial expressions presented under conditions of restricted awareness. Cognition and Emotion, 13, 713-740.

Mukai, S., Gagnon, M., Iloputaife, I., Hamner, J. W., \& Lipsitz, L. A. (2003). Effect of systolic blood pressure and carotid stiffness on baroreflex gain in elderly subjects. The Journals of Gerontology: Series A, 58, M626-M630.

Mulder, L. J. M. (1988). Assessment of cardiovascular reactivity by means of spectral analysis (Unpublished doctoral thesis). Rijksuniversiteit.

Mussgay, L., \& Rüddel, H. (2004). Autonomic dysfunctions in patients with anxiety throughout therapy. Journal of Psychophysiology, 18, 27-37.

Nabi, H., Hall, M., Koskenvuo, M., Singh-Manoux, A., Oksanen, T., Suominen, S., .. V Vahtera, J. (2010). Psychological and somatic symptoms of anxiety and risk of coronary heart disease: the Health and Social Support Prospective Cohort Study. Biological Psychiatry, 67, 378-385.

Neale, M. C., Hunter, M. D., Pritikin, J. N., Zahery, M., Brick, T. R., Kirkpatrick, R. M., ... Boker, S. M. (2016). OpenMx 2.0: extended structural equation and statistical modeling. Psychometrika, 81, 535-549.
Neale, M. C., Hunter, M. D., Pritkin, J., Zahery, M., Brick, T. R., Kirkpatrick, R. M., . . Boker, S. M. (2016). OpenMx 2.0: extended structural equation and statistical modeling. Psychometrika, 81, 535-549.

Neale, M. C., \& Miller, M. B. (1997). The use of likelihood-based confidence intervals in genetic models. Behavior Genetics, 27, 113-120.

Nivard, M. G., Dolan, C. V., Kendler, K. S., Kan, K.-J., Willemsen, G., Beijsterveldt, C. E. M. van, ... Boomsma, D. I. (2015). Stability in symptoms of anxiety and depression as a function of genotype and environment: A longitudinal twin study from ages 3 to 63 years. Psychological Medicine, 45, 1039-1049.

Nolte, I. M., Munoz, M. L., Tragante, V., Amare, A. T., Jansen, R., Vaez, A., de Geus, E. (2017). Genetic loci associated with heart rate variability and their effects on cardiac disease risk. Nature Communications, 8, 15805. https:// doi.org/10.1038/ncomms15805

North, B. J., \& Sinclair, D. A. (2012). The intersection between aging and cardiovascular disease. Circulation Research, 110, 1097-1108.

Osztovits, J., Horváth, T., Littvay, L., Steinbach, R., Jermendy, Á., Tárnoki, Á., .. Jermendy, G. (2011). Effects of genetic vs. Environmental factors on cardiovascular autonomic function: A twin study. Diabetic Medicine, 28, 1241-1248.

Paneni, F., Diaz Cañestro, C., Libby, P., Lüscher, T. F., \& Camici, G. G. (2017). The aging cardiovascular system: understanding it at the cellular and clinical levels. Journal of the American College of Cardiology, 69, 1952-1967.

Petkus, A. J., Gatz, M., Reynolds, C. A., Kremen, W. S., \& Wetherell, J. L. (2016). Stability of genetic and environmental contributions to anxiety symptoms in older adulthood. Behavior Genetics, 46, 492-505.

Pittig, A., Arch, J. J., Lam, C. W. R., \& Craske, M. G. (2013). Heart rate and heart rate variability in panic, social anxiety, obsessive-compulsive, and generalized anxiety disorders at baseline and in response to relaxation and hyperventilation. International Journal of Psychophysiology, 87, 19-27.

Pratt, L. A., Druss, B. G., Manderscheid, R. W., \& Walker, E. R. (2016). Excess mortality due to depression and anxiety in the United States: results from a nationally representative survey. General Hospital Psychiatry, 39, 39-45.

Purves, K. L., Coleman, J. R. I., Meier, S. M., Rayner, C., Davis, K. A. S., Cheesman, R., ... Eley, T. C. (2019). A major role for common genetic variation in anxiety disorders. Molecular Psychiatry. Epub ahead of print. https://doi.org/10.1038/s41380-019-0559-1

Riese, H., Rijsdijk, F. V., Ormel, J., van Roon, A. M., Neeleman, J., \& Rosmalen, J. G. (2006). Genetic influences on baroreflex sensitivity during rest and mental stress. Journal of Hypertension, 24, 1779-1786.

Riese, H., Rijsdijk, F. V., Snieder, H., \& Ormel, J. (2013). The Twin Interdisciplinary Neuroticism Study. Twin Research and Human Genetics, 16, 268-270.

Riese, H., Rosmalen, J. G. M., Ormel, J., Van Roon, A. M., Oldehinkel, A. J., \& Rijsdijk, F. V. (2007). The genetic relationship between neuroticism and autonomic function in female twins. Psychological Medicine, 37, 257-267.

Robbe, H. W., Mulder, L. J., Rüddel, H., Langewitz, W. A., Veldman, J. B., \& Mulder, G. (1987). Assessment of baroreceptor reflex sensitivity by means of spectral analysis. Hypertension, 10, 538-543.

Roest, A. M., Martens, E. J., de Jonge, P., \& Denollet, J. (2010). Anxiety and risk of incident coronary heart disease: A meta-analysis. Journal of the American College of Cardiology, 56, 38-46.

Sanchez-Gonzalez, M. A., Guzik, P., May, R. W., Koutnik, A. P., Hughes, R., Muniz, S., ... Fincham, F. D. (2015). Trait anxiety mimics age-related cardiovascular autonomic modulation in young adults. Journal of Human Hypertension, 29, 274-280.

Sandercock, G. R. H., Bromley, P. D., \& Brodie, D. A. (2005). The reliability of short-term measurements of heart rate variability. International Journal of Cardiology, 103, 238-247.

Shaffer, F., McCraty, R., \& Zerr, C. L. (2014). A healthy heart is not a metronome: an integrative review of the heart's anatomy and heart rate variability. Frontiers in Psychology, 5. https://doi.org/10.3389/fpsyg.2014.01040

Sigurdsson, M. I., Waldron, N. H., Bortsov, A. V., Smith, S. B., \& Maixner, W. (2018). Genomics of cardiovascular measures of autonomic tone. Journal of Cardiovascular Pharmacology, 71, 180-191.

Snieder, H., van Doornen, L. J. P., Boomsma, D. I., \& Thayer, J. F. (2007). Sex differences and heritability of two indices of heart rate dynamics: A twin study. Twin Research and Human Genetics, 10, 364-372. 
Swenne, C. A. (2013). Baroreflex sensitivity: mechanisms and measurement. Netherlands Heart Journal, 21, 58-60.

Thayer, J. F., Friedman, B. H., \& Borkovec, T. D. (1996). Autonomic characteristics of generalized anxiety disorder and worry. Biological Psychiatry, 39, 255-266.

Thayer, J. F., \& Lane, R. D. (2000). A model of neurovisceral integration in emotion regulation and dysregulation. Journal of Affective Disorders, 61, 201-216.

Thayer, J. F., Yamamoto, S. S., \& Brosschot, J. F. (2010). The relationship of autonomic imbalance, heart rate variability and cardiovascular disease risk factors. International Journal of Cardiology, 141, 122-131.

Van Roon, A. M., Mulder, L. J. M., Althaus, M., \& Mulder, G. (2004). Introducing a baroreflex model for studying cardiovascular effects of mental workload. Psychophysiology, 41, 961-981.

Virtanen, R., Jula, A., Salminen, J. K., Voipio-Pulkki, L.-M., Helenius, H., Kuusela, T., \& Airaksinen, J. (2003). Anxiety and hostility are associated with reduced baroreflex sensitivity and increased beat-to-beat blood pressure variability. Psychosomatic Medicine, 65, 751-756.

Vogelzangs, N., Seldenrijk, A., Beekman, A. T. F., van Hout, H. P. J., de Jonge, P., \& Penninx, B. W. J. H. (2010). Cardiovascular disease in persons with depressive and anxiety disorders. Journal of Affective Disorders, 125, 241-248.

Wang, S.-M., Yeon, B., Hwang, S., Lee, H.-K., Kweon, Y.-S., Lee, C. T., . . . Lee, K.-U. (2013). Threat-induced autonomic dysregulation in panic disorder evidenced by heart rate variability measures. General Hospital Psychiatry, 35, 497-501.

Watkins, L. L., Blumenthal, J. A., \& Carney, R. M. (2002). Association of anxiety with reduced baroreflex cardiac control in patients after acute myocardial infarction. American Heart Journal, 143, 460-466.

Watkins, L. L., Grossman, P., Krishnan, R., \& Blumenthal, J. A. (1999). Anxiety reduces baroreflex cardiac control in older adults with major depression. Psychosomatic Medicine, 61, 334-340.

Watkins, L. L., Grossman, P., Krishnan, R., \& Sherwood, A. (1998). Anxiety and vagal control of heart rate. Psychosomatic Medicine, 60, 498-502.

Yamamoto, S. S., \& Brosschot, J. F. (2010). The relationship of autonomic imbalance, heart rate variability and cardiovascular disease risk factors. International Journal of Cardiology, 141, 122-131.

Yeragani, V. K., Tancer, M., Seema, K. P., Josyula, K., \& Desai, N. (2006). Increased pulse-wave velocity in patients with anxiety: implications for autonomic dysfunction. Journal of Psychosomatic Research, 61, 25-31. 